\title{
Supporting Self-regulated Learning with Digital Media using Motivational Regulation and Metacognitive Prompts
}

\author{
Martin Daumiller \\ University of Augsburg
}

\author{
Markus Dresel \\ University of Augsburg
}

\begin{abstract}
Studying with digital media, learners often struggle because of inadequate self-regulation. Previous research presented clear evidence of metacognitive prompts being effective in supporting learning with digital media. This study examines the potential of motivational regulation prompts, which are assumed to additionally support self-regulated learning. During a 50-min learning session in a digital media learning environment, 215 university students received either no prompts, only metacognitive prompts, only motivational regulation prompts, or both types of prompts. Task value, metacognitive control, task-related learning activities, and knowledge were assessed at a pretest, posttest, and follow-up. The results replicated known positive effects of metacognitive prompts and revealed additional supportive effects of motivational regulation prompts on all dependent variables. Path modeling of the experimentally induced changes was in line with a theoretical model specifying proximal and distal effects of both prompts. Altogether, this indicates that especially motivational regulation prompts could be an effective scaffold to support SRL with digital media.
\end{abstract}

Keywords: self-regulated learning; prompting; motivational regulation; metacognitive control; digital media

(C) 2019, Taylor \& Francis Online. The official citation for this manuscript is: Daumiller, M., \& Dresel, M. (2019). Supporting self-regulated learning with digital media using motivational regulation and metacognitive prompts. Journal of Experimental Education, 87(1), 161-176. https://doi.org/10.1080/00220973.2018.1448744. This paper is not the copy of record and may not exactly replicate the final, authoritative version of the article. The final article will be available, upon publication, via its DOI.

Learning with digital media offers many promising benefits that are often difficult to realize in traditional learning contexts. For instance, the learner can independently study a wide array of learning material, actively make sense of the learning context on his or her own, and differentiate instructional paths and the pace of learning based on domain knowledge and habits, allowing for higher cognitive engagement and an individual adjustment of the learning path (Moos \& Azevedo, 2008). However, learners often struggle when working with digital media learning environments, as they do not self-regulate their learning adequately, for example do not choose adequate learning materials, ignore previous knowledge and personal strengths, fail to adapt their learning strategies or do not elaborate the learning content sufficiently (e.g.,

Correspondence concerning this article should be addressed to Martin Daumiller, Department of Psychology, University of Augsburg, Universitätsstr. 10, 86159 Augsburg, Germany; Martin.Daumiller@phil.uni-augsburg.de.

We have no known conflicts of interest to disclose. This research was supported by the German Federal Ministry of Education and Research (Grant number 01PK15002A).
Azevedo, 2008). Consequently, various methods for supporting self-regulated learning (SRL) in digital media have been examined (Puntambekar \& Hubscher, 2005). One promising approach is prompting learners to carry out specific self-regulated learning activities by presenting questions or hints, which support them in applying learning strategies during task-performance (Bannert \& Mengelkamp， 2013; Reigeluth \& Stein, 1983; Schmidt, Maier, \& Nückles, 2012). There is a great body of research depicting the effectiveness of SRL prompts in encouraging students to employ cognitive strategies, however, little research is directed towards the employment of metacognitive and motivational regulation strategies (Devolder, van Braak, \& Tondeur, 2012). Particularly, almost nothing is known on the potential of prompting motivational regulation strategies, despite their already demonstrated relevance for effective learning and their theoretically assumed superordinate function in self-regulated learning (Boekaerts, 1999; Schwinger, Steinmayr, \& Spinath, 2009; Wolters, 2003). The present research aims to examine this potential. 


\section{Self-Regulated Learning}

In essence, SRL can be defined as autonomous efforts undertaken by learners to initiate, sustain, and alter cognitions, affects, and behaviors that are systematically oriented towards the attainment of learning goals (Boekaerts, Pintrich, \& Zeidner, 2005; Schunk \& Zimmerman, 2012; Winne \& Hadwin, 2010). In order to describe SRL, multiple models exist that focus more on the components or more on the process of self-regulated learning (Winne \& Perry, 2000).

The component model presented by Boekaerts (1999) depicts SRL in three layers and is helpful to conceptualize the role of motivational regulation. The innermost layer describes cognitive strategies. These regulate information-processing modes in order to support the direct assimilation of information by helping learners attend to, select, elaborate on, and organize information so that deep-level understanding is possible by employing strategies such as activation of prior knowledge, memorization, transformation, elaboration, etc. (see also Weinstein \& Hume, 1998). Describing metacognitive control, the middle layer pertains to higher-order learning strategies that are employed by the learner to successfully coordinate the use of the lower ordered cognitive strategies. They are used to plan, monitor, reflect, and/or evaluate the learning process (see also Zimmerman, 1986). The outermost layer concerns regulation of the self, i.e., is directed at the learners' expectations and motivation, and also shields from influences and behaviors not related to his or her current learning goal. Motivation and its regulation are central in this layer and guide the lower ordered metacognitive control, which in turn controls the employment of cognitive strategies.

\section{Motivation and Motivational Regulation as Core Parts of SRL}

As conceptualized in the model by Boekaerts (1999) and many other SRL models (e.g., Pintrich, 2004, Winne \& Hadwin, 1998, Zimmerman, 2000), learners' motivation (i.e., their willingness to work toward or complete a particular activity or goal) plays a prominent role in SRL, with achievement values being of particular gravitas: "Because the most effective self-regulatory techniques require anticipation, concentration, effort, and careful self-reflection, they are used only when the skill or it's outcome is highly valued" (Zimmerman, 2000, p. 27). Indeed, Pintrich and Zusho (2002) stress the importance of activating values and beliefs about one's capability to complete a task successfully, with valued activities leading to learners devoting more time for planning, monitoring, and regulating of said task (cf. Zimmerman, 2000). Specifically, research unveils that cognitive and metacognitive SRL strategies depend on motivation, none more so than task value (Pintrich \& De Groot, 1990; Wigfield, Hoa, \& Klauda, 2008). Therefore we will focus chiefly on task value and its regulation.

Ensuing from basic research at the end of the 1990s (e.g., Dewitte \& Lens, 1999; Garcia，1999; Pintrich, 1999, 2000; Wolters, 1999), there has recently been a research focus on the regulation of motivation in general learning contexts (Schwinger et al., 2009; Winne \& Hadwin, 2012; Wolters, 2003). According to Wolters (2003), motivational regulation can be understood as the deliberate guidance of one's motivation with the intention to enhance, supplement, or retain it by means of specific strategies such as the enhancement of personal significance, self-consequating, or mastery self-talk. It is considered an integral component (e.g., as a form of resource management) within the larger system of SRL in most theoretical conceptualizations (e.g., Boekaerts, 1997; Pintrich, 2000; Zimmerman, 2000). The presumption is that effective learners employ motivational regulation strategies to initiate the learning process, to shield it against interruptions, and to invest sustained effort in cognitive learning activities. Indeed, studies indicate that the use of motivational regulation strategies while learning is associated with better learning behavior, effort, and learning results (e.g., Engelschalk, Steuer, \& Dresel, 2017; Grunschel, Schwinger, Steinmayr, \& Fries, 2016; Schwinger, et al., 2009; Wolters, 1999).

Different motivational regulation strategies have been distinguished (e.g., Wolters, 1999; Wolters \& Benzon, 2013; Schwinger, von der Laden, \& Spinath, 2007). In particular, task value based strategies have proven to be effective (Schwinger, et al, 2007). Task value based strategies have also been shown to be successful in small interventions. For example, Hulleman and Harackiewicz (2009) asked students to find connections between their own interests and the taught topic (i.e., in the classification of task values by Wigfield and Eccles, 2000, attainment value was addressed). In comparison to a control group, these students substantially increased their interest in the topic of the course over time. Similarly, also the regulation of instrumental value and intrinsic value as other task value types suggested by Wigfield and Eccles (2000) has been documented to support learning (e.g., modify- 
ing a task in a way that makes it more exciting and interesting; e.g., Sansone, Weir, \& Harpster, 1992; Schwinger et al., 2009, 2012). Against the background of these findings, we use task value based strategies to examine the effects of prompting motivational regulation strategies in this study.

\section{SRL with Digital Media}

With digital media learning environments usually providing a multitude of information in different representations and various possibilities to manipulate such information, a successful learner has to constantly decide what to do next and evaluate how the retrieved information is relevant for his or her learning goals while taking prior knowledge, self-knowledge, and own motivational factors into consideration (Lin \& Lehman, 1999). At the same time, the learner has to actively monitor the effectiveness of the learning activities and his or her understanding of the topic (Azevedo, 2008). Thus, learners in digital media must be highly self-regulated as otherwise learning effectiveness may be low (Kauffman, 2004).

Many empirical studies have shown that when studying with digital media, the frequency of the use of SRL strategies is consistently and positively associated with the quality of learning outcomes (for an overview, see Winters, Greene, \& Costich, 2008). Especially the use of elaboration strategies and metacognitive strategies is effective while working on challenging topics (Azevedo \& Hadwin, 2005; Graesser, McNamara, \& VanLehn, 2005). Additionally, the regulation of the learning effort on the behavioral level (particularly in terms of persisting task related activities also in the face of difficulties) was linked with learning outcomes (Schwinger, Steinmayr, \& Spinath, 2009). On the other hand, researchers also found that in digital media learning settings, many learners do not spontaneously exhibit effective SRL (Azevedo \& Cromley, 2004; Nückles, Schwonke, Berthold, \& Renkl, 2004), and students who lack self-regulation of learning are less likely to succeed (Hsu, Ching, Mathews, \& CarrChellman, 2009; Li \& Irby, 2008). Consequently, digital media learning environments should support effective SRL (cf. Azevedo, 2005; Azevedo \& Hadwin, 2005). Although appearing important for learning with digital media, motivational regulation and its effects on learning behavior and learning results have not yet been object of empirical research in this domain until now.

\section{Prompts as Scaffolds to Support SRL with Digital Media}

Having conducted a comprehensive literature review, Devolder et al. (2012) conclude that the presentation of prompts appears to be the most effective way to scaffold SRL in computer based learning environments. Prompts are procedures to induce and stimulate cognitive, metacognitive, volitional and/or cooperative activities during learning (Bannert \& Mengelkamp, 2013). Following Reigeluth and Stein (1983), they can be understood as strategy activators in the form of questions or hints that support learners in applying procedural knowledge. Hence, they do not present new information but help to stimulate the recall of procedures and concepts, trigger the execution of actions and techniques, or induce various learning strategies (cf. Reigeluth \& Stein, 1983). There is ample evidence propounding that prompting cognitive SRL strategies leads to learners employing more of those strategies and achieving better learning outcomes (Berthold, Nückles, \& Renkl, 2007; Davis, 2000; Rosenshine, Meister, \& Chapman, 1996).

Moreover, a growing body of research indicates that metacognitive prompts are at least as effective as they are superordinate, more universal and function as regulators of a flexible use of cognitive strategies (Bannert, 2009; Bannert \& Mengelkamp, 2013; Bannert \& Reimann, 2012; Hübner, Nückles, \& Renkl, 2010; Lin, 2001; Lin \& Lehman, 1999; Schmidt et al., 2012). For example, in an experiment by Bannert, Hildebrand, and Mengelkamp (2009), university students were instructed on why and how to use metacognitive activities and received prompts to apply them during a learning session. Controlling for prior knowledge and metacognitive knowledge, students in the experimental group demonstrated better learning outcomes than students in the control group. A study by Hübner et al. (2010) examined high-school students who wrote computer-assisted learning protocols about a videotaped lecture they had previously seen. Their instruction either included six cognitive prompts for organization and elaboration (e.g., "Which examples can you think of that illustrate, confirm, or conflict with the learning contents?"), six metacognitive prompts for monitoring and planning (e.g., "Which main points haven't I understood yet?"), a mixture of these two forms, or no prompts at all. The results showed that students who received any form of prompts outperformed students in the control group in comprehension and transfer tests, and that when sufficient opportunities to accomplish remedial activities were given, the mixed condition resulted in the best effects. 
Summarized, there is clear evidence for the effectiveness of cognitive prompts and promising but still mixed results for metacognitive prompts. Motivation has generally been considered as important for learning with digital media, but has only scarcely been examined in research in this field (Chiu, Sun, Sun, \& Ju, 2007; van Loon, Ros, \& Martens, 2012), while to the best of our knowledge motivational regulation prompts are uninvestigated until now (cf. Lehmann, Hähnlein, \& Ifenthaler, 2014). However, as motivational regulation constitutes a quintessential and universal aspect of SRL that is functional for effective task-related learning activities and likely to impinge on the employment of metacognitive and in turn cognitive strategies, the prompting of motivational regulation strategies appears highly auspicious. This is especially so in comparison to cognitive and metacognitive strategies, which are more limited, temporary and - when prompted over a longer period of time-even associated with a decline in motivation (Nückles, Hübner, Dümer, \& Renkl, 2010). In correspondence to the importance of task value for motivation and SRL, especially the regulation of one's task value appears as to be an important motivational regulation strategy. In the light of relatively brief task value interventions (e.g., Hulleman \& Harackiewicz, 2009), it can be assumed that task value regulation can also be induced with prompts when learning with digital media (e.g., with prompts that ask students to reflect upon the personal relevance of the current learning material). Specifically, this assumption can be theoretically decomposed in two presumptions that are well supported by theoret ical and empirical work as described above: (a) prompting is an effective measure to enhance strategy application while learning with digital media, and (b) task value can be regulated effectively by applying motivational regulation strategies (e.g., Bannert \& Mengelkamp, 2013; Devolder et al., 2012; Engelschalk et al., 2016; Schwinger et al., 2009; Wolters, 2003).

\section{Research Questions}

The present study aims to describe and explain the individual and interaction effects of metacognitive prompts and motivational regulation prompts. Figure 1 depicts the assumed effects on the learners' task-related learning activities (in terms of the use of cognitive strategies and the persistence of learning) and knowledge acquisition. This model constitutes the theoretical foundation of the hypotheses tested:

$\left(\mathrm{H}_{1}\right)$ The presentation of metacognitive prompts promotes the use of metacognitive strategies, task-related learning activities (use of cognitive strategies, persistence), and knowledge acquisition.

$\left(\mathrm{H}_{2}\right)$ The presentation of motivational regulation prompts leads to higher task value and promotes the use of metacognitive strategies, task-related learning activities, and knowledge acquisition.

$\left(\mathrm{H}_{3}\right)$ Presenting metacognitive and motivational regulation prompts together promotes the use of metacognitive strategies, task-related learning activities, and knowledge acquisition better than presenting only one type of prompt alone.

It was assumed that all effects occur immediately and are temporary stable over a substantial period of time.

On a more general level we aimed to confirm that the changes in the outcome variables - that are assumed to be induced by the treatment - were as a whole in line with the assumptions made in our model (see

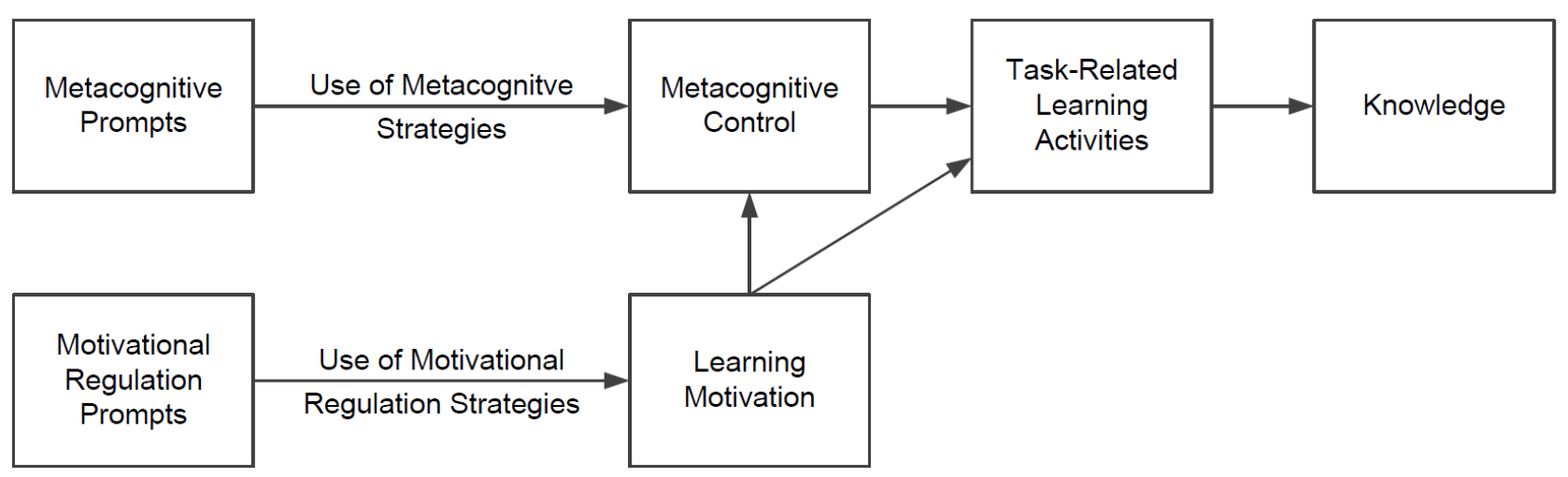

Figure 1. Model proposing proximal and distal effects of metacognitive prompts and motivational prompts. 
Figure 1). Specifically, we tested the assumption made in this model that motivational regulation prompts function on a superordinate level (cf. Boekaerts, 1999):

$\left(\mathrm{H}_{4}\right)$ Motivational regulation prompts promote not only task value but also metacognitive control (while metacognitive prompts solely promote metacognitive control) and, thus, promote task-related learning activities not only directly but also indirectly (via metacognitive control).

\section{Method}

An experimental design was realized in which university students worked for approx. $50 \mathrm{~min}$ on a digital media learning environment in a standardized setting. Their task value, metacognitive control, task-related activities and knowledge were assessed directly before (T1, pretest) and directly after (T2, posttest) working with the digital media learning environment as well as in a follow-up (T3) one week later. Additionally, student performance in content-related tasks in an end-ofterm exam was assessed (took place ten weeks after working with the digital media learning environment, T4). The students were randomly assigned to one of four experimental conditions, receiving - implemented in the learning environments-(a) either no prompts, (b) metacognitive prompts, (c) motivational regulation prompts, or (d) both types of prompts.

\section{Learning Environment}

A web-based learning environment was developed with the criteria of providing enough opportunities to utilizing SRL strategies and also requiring these strategies to achieve satisfactory learning results. To attain this, the topic of psychological research methods was selected because it constituted a topic (a) of which the students had little prior knowledge, (b) that is typically perceived as rather boring and unappealing (cf. Reid \& Petocz, 2002), and (c) which is considered at least moderately difficult (cf. Pan \& Tang, 2004). Furthermore, it was essential that the learning environment be straightforward in usability and presented the SRL prompts in a salient and non-impeding manner. Based upon these requirements, the web-based learning environment presented its content spanned over 12 subpages (including three video clips). They could be accessed over a starting page, where a non-linear overview of the content was given. Results of pilot testing (with six students) indicated that the learning environment's content, difficulty and design were consid- ered - as intended - average. Therefore, to learn effectively, the use of self-regulated learning strategies was required.

\section{Prompts}

Altogether 12 metacognitive and 12 motivational regulation prompts were constructed. They contained an encouragement of reflective processes (e.g., "Think about"), followed by a definition of the strategy (e.g., "the personal relevance") and, for motivational regulation prompts, a specification of the concrete subject (e.g., "of this learning material"). Metacognitive prompts focused on aspects of the phase of performance monitoring (Zimmerman, 2000) differentiating between the monitoring of strategy use, the monitoring of the learning progress, and the regulation of learning strategies. For motivational regulation prompts, the well-established theoretical differentiation of task value in utility value, attainment value, and intrinsic value (Wigfield \& Eccles, 2000) was deployed (the aspect of cost was excluded as it was inappropriate for the fixed learning scenario used in the study). As such, the motivational regulation prompts addressed all three aspects of task value. The final prompts were obtained through a systematic variation of the formulations for the encouragement of the reflective processes, the specific strategies, and syntax. ${ }^{1}$ Great attention was put on formulating the prompts in a general manner, eschewing unnecessary expletives, simplifying the content, and not insinuating any deficiencies in the learner's motivation or strategy use in order to reach him or her directly without triggering reactance.

\section{Participants}

Overall, 271 German undergraduates participated voluntarily in the study. Fifty-six participants were excluded from the original sample because they did not recognize the presented prompts in a sufficient manner. $^{2}$ Therefore the final sample included in the analyses was comprised of 215 students (175 females, 40 males). Participants were mainly teacher trainees $(61.4 \%)$ and B.A. Education students $(36.4 \%)$ who were on average in their 2.4 th $(S D=1.9)$ semester with a mean age of $21.4(S D=4.1)$ years.

\section{Measures}

All measures were used in all measurement points, with the exception of the amount of seen subpages and the use of the prompted strategies while working with 
the digital media environment (in terms of a manipulation check; both only T2) and exam performance (only T4). Measures were generally focused on the addressed domain in T1 ("When learning psychology ...") and on the specific topic of the learning environment in T2 und T3 ("When learning about psychological research methods ...”). In T2 this was furthermore specified by asking the participants to refer their answers to their prior learning experience. Unless otherwise noted, all items were presented with Likert-type scales ranging from 1 (strongly disagree) to 6 (strongly agree).

Subpages Seen. As a background control variable, the amount of seen subpages during learning ("How many text pages did you address in depth?") were taken as proximal indicators of the extent of the learners' activities.

Use of Prompted Strategies. To test the proximal effects of the prompting intervention (also in terms of a manipulation check), the immediate pursuit of the prompted strategies while working with the digital media environment was assessed in T2 with three items for metacognitive and motivational regulation activities each. These items asked on Likert-type response scales ranging from 1 (never) to 5 (always) how frequently the learner followed the prompts' incitement. They were constructed by using the most prototypic formulations of each of the prompt subcategories for metacognitive (e.g., "Working with the learning environment, I often reflected on whether I am proceeding effectively"; $\alpha=.60$ ) and motivational regulation (e.g., "Working with the learning environment, I often thought about what I can use the learning contents for."; $\alpha=.65$ ) prompts. ${ }^{3}$

Metacognitive Control. Corresponding with the prompts' focus, monitoring and regulation in the face of difficulties of learning actions were assessed. Monitoring was measured by an adapted scale of Baumert, Heyn, and Köller (1992) with seven items directed at the students' supervision and control (e.g., "When learning psychology, I periodically reflect on which aspects I have already understood"; $\alpha=.80-.86)$. With eight items, that were constructed by extending and adapting a five item scale by Gold and Souvignier (2000), regulation in the face of difficulties was assessed (e.g., "If I don't understand something when learning about psychological research methods, I try to find out what exactly causes the difficulties"; $\alpha=.81-$ .88). Justified by moderate to large correlations between these three aspects $(r=.49-.59)$, their mean was taken to represent the participants' metacognitive control in a single variable $(\alpha=.84-.92)$.
Task Value. As an aspect of the learning motivation that is most relevant in the present context, participants' task value was measured with a scale that was successfully used in previous studies (Ziegler, Dresel, \& Stöger, 2008) and adapted for the present study. With the adapted scale, intrinsic value (e.g., "I greatly enjoy engaging with psychological research methods"; $\alpha=.87-.89$ ), attainment value (e.g., "Knowing a lot about psychological research methods is very important to me personally "; $\alpha=.90-.91$ ), and instrumental value (e.g., "Knowledge about psychological research methods is useful"; $\alpha=.79-.87$ ) were assessed with three items each. Since we were interested in the general effects of the motivational regulation prompts - that equally addressed all three aspects of task value - these subscales expressing the students' motivational regulation were consolidated into one variable $(\alpha=.92-.93)$ that was used in the analyses. ${ }^{4}$ This procedure was also justified by rather large correlations $(r=.59-.80)$ between the three task value facets.

Task-related Learning Activities. Assessments were made of two aspects, namely, elaboration as a cognitive strategy of pivotal importance, and persistence as a fundamental behavioral aspect. Students' elaboration was assessed with a scale that was already used in previous research (e.g., Dresel \& Haugwitz, 2006) and adapted to the learning context (e.g., "When learning psychology, I try to find connections between what I know already and the current topics"; $\alpha=.82$ .89). Persistence was measured by adapting a scale from Wolters (2004) with three items (e.g., "I continue even if I experience difficulties"; $\alpha=.75-.80)$. Although elaboration and persistence express different aspects, they correlated sufficiently $(r=.43-.67)$ to justify their aggregation in one main variable to simplify the realized analyses $(\alpha=.83-.88)$. Such an aggregation of different learning activities is not uncommon in the literature to allow for parsimony modelling (e.g., VanZile-Tamsen \& Livingstone, 1999).

Knowledge. Content knowledge related to the learning topic was assessed by administering a multiple-choice test containing 16 true-or-false items in T1 and 16 additional items in T2 and T3. As the research questions did not require statements about the absolute knowledge of the students, but merely about differential learning gains in dependence of the allocation to the treatment groups, it sufficed to construct a rather heterogeneous test with high content validity that could be interpreted in its overall score by comparing the rankorder of the students. The tests were developed by first formulating a pool of 82 items that covered the content of the learning environment. Afterwards, a pilot study 
$(N=22)$ was conducted to determine for each main content aspect the most representative items with adequate difficulty, which consequently were selected for the tests. Thereby, the first four questions were formed by the easier items to be able to adequately determine the participants' baseline knowledge. In the analyses, the proportion of correct items was used.

Exam Performance. Content knowledge was also measured ten weeks after participation in the learning environment by obtaining students' scores on eight questions (each with four true-or-false answering options that functioned as items) concerning psychological research methods from a multiple-choice exam at the end of the semester. Again, the proportion of correct items was used in the analyses.

\section{Analyses}

Two (presentation of metacognitive prompts yes or no) $\mathrm{x}$ two (presentation of motivational regulation prompts yes or no) $\mathrm{x}$ two (posttest vs follow-up) factorial analyses of variance with repeated measurement on the third factor and the respective pretest-scores as covariates were performed in order to test the hypotheses. The effect on exam performance was tested with an analogous analysis with two experimental factors and T1 knowledge as a covariate (i.e., without the within subject time factor). Preliminarily, analyses of variance with the two experimental factors were performed, in which we investigated the use of prompted strategies (manipulation check) and the amount of subpages seen (to confirm that the effects of the prompts were not confounded with the time on task) as dependent variables.

In order to test whether the treatment induced changes in the four outcome variables are in line with the assumptions made in our model (see Figure 1), two path models have been estimated using change scores reflecting the changes from pretest to posttest and follow-up, respectively (i.e., all dependent variables were adjusted for their corresponding pretest scores). Thus, the paths included in these change models correspond directly to effects of the two types of SRL prompts on students' task value, their metacognitive control, their task-related learning activities, and their content knowledge.

Table 1

Descriptive Statistics and Bivariate Correlations

\begin{tabular}{|c|c|c|c|c|c|c|c|c|c|c|c|c|c|c|c|c|}
\hline & 1 & 2 & 3 & 4 & 5 & 6 & 7 & 8 & 9 & 10 & 11 & 12 & 13 & 14 & 15 & 16 \\
\hline \multicolumn{17}{|l|}{ 1. Subpages seen T2 } \\
\hline $\begin{array}{l}\text { 2. Use of metacognitive } \\
\text { strategies } \mathrm{T} 2\end{array}$ & -.06 & & & & & & & & & & & & & & & \\
\hline $\begin{array}{l}\text { 3. Use of motivational } \\
\text { regulation strategies } \mathrm{T} 2\end{array}$ & .07 & .37 & & & & & & & & & & & & & & \\
\hline 4. Metacognitive Control T1 & .06 & .32 & .09 & & & & & & & & & & & & & \\
\hline 5. Metacognitive Control T2 & .05 & .49 & .20 & .67 & & & & & & & & & & & & \\
\hline 6. Metacognitive Control T3 & .04 & .44 & .20 & .60 & .66 & & & & & & & & & & & \\
\hline 7. Learning Motivation T1 & -.01 & .26 & .11 & .28 & .36 & .40 & & & & & & & & & & \\
\hline 8. Learning Motivation T2 & .04 & .32 & .04 & .29 & .46 & .45 & .51 & & & & & & & & & \\
\hline 9. Learning Motivation T3 & -.02 & .41 & .16 & .21 & .37 & .51 & .47 & .73 & & & & & & & & \\
\hline $\begin{array}{l}\text { 10. Task-related Learning } \\
\text { Activities T1 }\end{array}$ & .07 & .33 & .05 & .50 & .50 & .52 & .44 & .40 & .40 & & & & & & & \\
\hline $\begin{array}{l}\text { 11. Task-related Learning } \\
\text { Activities T2 }\end{array}$ & .10 & .37 & .10 & .47 & .64 & .64 & .23 & .44 & .44 & .68 & & & & & & \\
\hline $\begin{array}{c}\text { 12. Task-related Learning } \\
\text { Activities T3 }\end{array}$ & .04 & .36 & .10 & .48 & .74 & .74 & .26 & .42 & .50 & .68 & .76 & & & & & \\
\hline 13. Knowledge T1 & -.05 & .07 & -.02 & .13 & .17 & .09 & .13 & .15 & .15 & .12 & .17 & .11 & & & & \\
\hline 14. Knowledge $\mathrm{T} 2$ & .10 & .02 & -.09 & .04 & .09 & .04 & .08 & .08 & .07 & .14 & .16 & .10 & .39 & & & \\
\hline 15. Knowledge T3 & -.09 & .06 & -.01 & .09 & .11 & .14 & .11 & .11 & .21 & .14 & .18 & .18 & .29 & .45 & & \\
\hline 16. Exam performance $\mathrm{T} 4$ & -.07 & .02 & -.03 & .01 & .04 & .04 & .06 & .05 & .10 & .06 & .05 & .04 & .17 & .23 & .29 & \\
\hline$M$ & 7.16 & 3.33 & 3.27 & 4.01 & 4.04 & 4.07 & 4.56 & 3.73 & 3.64 & 4.22 & 4.13 & 4.11 & .59 & .58 & .57 & .62 \\
\hline$S D$ & 3.05 & 0.67 & 0.69 & 0.61 & 0.60 & 0.63 & 0.77 & 0.73 & 0.76 & 0.64 & 0.72 & 0.70 & 0.12 & 0.10 & 0.11 & 0.15 \\
\hline Skew & .63 & -.55 & -.61 & -.06 & -.19 & -.87 & -.40 & -.08 & -.17 & -.16 & -.17 & -.19 & -.01 & .11 & .37 & -.19 \\
\hline
\end{tabular}


Table 2

Sub-pages Seen and Use of Strategies in the Four Experimental Conditions

\begin{tabular}{|c|c|c|c|c|c|c|}
\hline & \multicolumn{2}{|c|}{$\begin{array}{c}\text { Sub-pages } \\
\text { seen }\end{array}$} & \multicolumn{2}{|c|}{$\begin{array}{l}\text { Use of meta- } \\
\text { cognitive } \\
\text { strategies }\end{array}$} & \multicolumn{2}{|c|}{$\begin{array}{c}\text { Use of } \\
\text { motivational } \\
\text { regulation } \\
\text { strategies }\end{array}$} \\
\hline & $M$ & $S D$ & $M$ & $S D$ & $M$ & $S D$ \\
\hline No prompts $(n=53)$ & 7.73 & 3.45 & 3.14 & 0.77 & 3.17 & 0.71 \\
\hline Metacognitive prompts $(n=55)$ & 6.75 & 3.18 & 3.48 & 0.72 & 3.14 & 0.75 \\
\hline Motivational regulation prompts $(n=53)$ & 7.16 & 2.62 & 3.27 & 0.61 & 3.27 & 0.70 \\
\hline Both types pf prompts $(n=54)$ & 7.02 & 2.94 & 3.44 & 0.51 & 3.51 & 0.52 \\
\hline
\end{tabular}

\section{Results}

\section{Preliminary Results}

Descriptive statistics and bivariate correlations for all measures can be found in Table 1. On average, students had little prior knowledge about psychological research methods, but demonstrated rather good task value and metacognitive control.

The students visited on average 7.2 out of the 12 subpages of the learning environment (Table 2). With regard to the amount of subpages seen, no statistically significant effects of the prompting conditions were observed, $F(1,211)<1.77, p>.18, \eta^{2}<.008$.

\section{Proximal Prompting Effects on Strategy Use (Manipulation Check)}

Concerning the use of metacognitive strategies while working with the digital media learning environ- ment (see Table 2), a statistically significant main effect of metacognitive prompts was evident, $F(1,211)=$ $7.91, p=.005, \eta^{2}=.036$. Analogously, a statistically significant main effect of motivational regulation prompts was observed for the use of motivational regulation strategies, $F(1,211)=2.80, p=.04, \eta^{2}=.011$. However, non-corresponding main effects (i.e., the effect of motivational regulation prompts on metacognitive strategy use and the effect of meta cognitive prompts on motivational regulation strategy use) were not statistically significant, $F(1,211)<1.24, p>.26, \eta^{2}$ $<.006$. This pattern of results indicates that the experimental manipulation was successful with the participants following the prompts they had been presented with. ${ }^{5}$

Table 3

Immediate and Stable Effects of Different Prompts

\begin{tabular}{|c|c|c|c|c|c|c|c|c|}
\hline & \multicolumn{2}{|c|}{$\begin{array}{l}\text { Metacognitive } \\
\text { control }\end{array}$} & \multicolumn{2}{|c|}{$\begin{array}{l}\text { Learning } \\
\text { motivation }\end{array}$} & \multicolumn{2}{|c|}{$\begin{array}{c}\text { Task-related } \\
\text { learning activities }\end{array}$} & \multicolumn{2}{|c|}{ Knowledge } \\
\hline & $F$ & $\eta^{2}$ & $F$ & $\eta^{2}$ & $F$ & $\eta^{2}$ & $F$ & $\eta^{2}$ \\
\hline \multicolumn{9}{|l|}{ Between subject effects } \\
\hline Metacognitive prompts (MC) & $5.40^{*}$ & .025 & 0.14 & .001 & $5.50 *$ & .026 & $8.26^{*}$ & .039 \\
\hline Motivational regulation prompts (MR) & $4.53 *$ & .021 & $6.66^{*}$ & .031 & $10.24 * *$ & .047 & $4.04 *$ & .019 \\
\hline Both prompts (MR x MC) & 0.40 & .002 & 1.71 & .008 & $7.10^{*}$ & .033 & 0.01 & $<.001$ \\
\hline \multicolumn{9}{|l|}{ Within subject effects } \\
\hline Time & 0.32 & .002 & 0.01 & $<.001$ & 0.29 & .001 & 0.25 & .001 \\
\hline Time $x$ MR & 0.01 & $<.001$ & 1.18 & .006 & 0.23 & .001 & 1.24 & .006 \\
\hline Time $\mathrm{x} M C$ & 0.01 & $<.001$ & 0.42 & .002 & 0.57 & .003 & 1.12 & .005 \\
\hline Time $x \mathrm{MC} \times \mathrm{MR}$ & 2.87 & .014 & 2.69 & .013 & 0.20 & $<.001$ & 0.83 & .004 \\
\hline
\end{tabular}

Note. Presented are the results from 2 (MR) x 2 (MC) × 2 (T2 vs. T3) factorial analyses of variance with repeated measurement on the third factor and the respective pretest-scores as a covariates. $d f_{1}=1$ and $d f_{2}=210$ for all effects.

$* * p<.01 . * p<.05$. 


\section{Prompting Effects on Metacognitive Control and Task Value}

Table 3 displays the results of the analyses of covariance with the repeatedly measured dependent variables. Figure 2 illustrates the estimated means of the dependent variables after controlling for the corresponding pretest variable - thus, differences between groups represent differential changes from pretest to posttest or follow-up, respectively.

Concerning the participants' metacognitive control (i.e., monitoring, regulation in the face of difficulties) we observed both a statistically significant main effect of metacognitive prompts and also a main effect of motivational regulation prompts (no significant interaction). Both types of prompts lead to an increase of students' reports of metacognitive control. None of the within-subject effects were statistically significant for metacognitive control, indicating that the observed effects were stable over time.

For participants' task value, a statistically significant main effect of motivational regulation prompts could be observed. However, the main effect of metacognitive prompting was not statistically significant (and no interaction between the two types of prompts was evident). This pattern indicates that the motivation of students who received motivational regulation prompts while working with the learning environment increased in relation to students who did not receive any or exclusively metacognitive prompts. Again, no within-subject effect was statistically significant, i.e., the observed effect remained stable over time.

\section{Prompting Effects on Task-Related Learning Activities and Knowledge}

With regard to students' task-related learning activities (i.e., use of cognitive learning strategies, persistence), we found statistically significant main effects for both motivational regulation and metacognitive prompts. Students who received any kind of prompts reported using cognitive strategies and being persistent to a larger extent. Here, also the interaction effect was statistically significant, indicating that students who received metacognitive prompts as well as motivational regulation prompts reported even more functional learning activities than students who received only one of the two types of prompts. Again, the analyses showed that these effects were stable over time.

Towards the participants' knowledge of psychological research methods, a statistically significant main effect for metacognitive prompts as well as for motivational regulation prompts was observed, whilst the interaction of both types of prompts was not statistically significant. This pattern indicates that presenting any kind of prompts leads to better knowledge acquisition when studying with the learning environment, but that the combination of both prompts did not offer an additive effect. As in all previous cases, the effects were revealed to be stable over time.

\section{Prompting Effects on Exam Performance}

Concerning students' results on the questions addressing psychological research methods on the exam at the end of the semester (after controlling for T1 knowledge), we still found a statistically significant main effect of motivational regulation prompts $\left(F(1,195)=3.23, p=.04, \eta^{2}=.016\right)$, indicating a better performance for students who received motivational regulation prompts. ${ }^{6}$ However, the effect of metacognitive prompts $\left(F(1,195)=0.14, p=.35, \eta^{2}=.001\right)$ and the interaction $\left(F(1,195)=0.72, p=.40, \eta^{2}=.004\right)$ that were observed for T2 and T3 knowledge, were not statistically significant.

\section{Relationships between Changes Induced by SRL Prompts}

Results from path modelling the changes from pretest to posttest and follow-up, respectively, are presented in Figure 3. All paths derived from the proposed model (see Figure 1) were statistically significant, except one path from changes in task value to changes in task-related learning activities in T2 with $p=.051$. Subsequently estimated indirect effects indicated that the changes in task value led nevertheless to changes in task-related learning activities at both measurment points and that these effects were partially mediated by metacognitive control (T2: $\beta=.10, \mathrm{SE}=.03, p<.001$; $\mathrm{T} 3: \beta=.17, \mathrm{SE}=.03, p<.001)$.

\section{Discussion}

The present research addressed how prompts support learning in digital media. Specifically, it investigated the impact of motivational regulation prompts, in addition to metacognitive prompts, on students' task value, metacognitive control, task-related learning activities, and knowledge. Strengths of the present work 

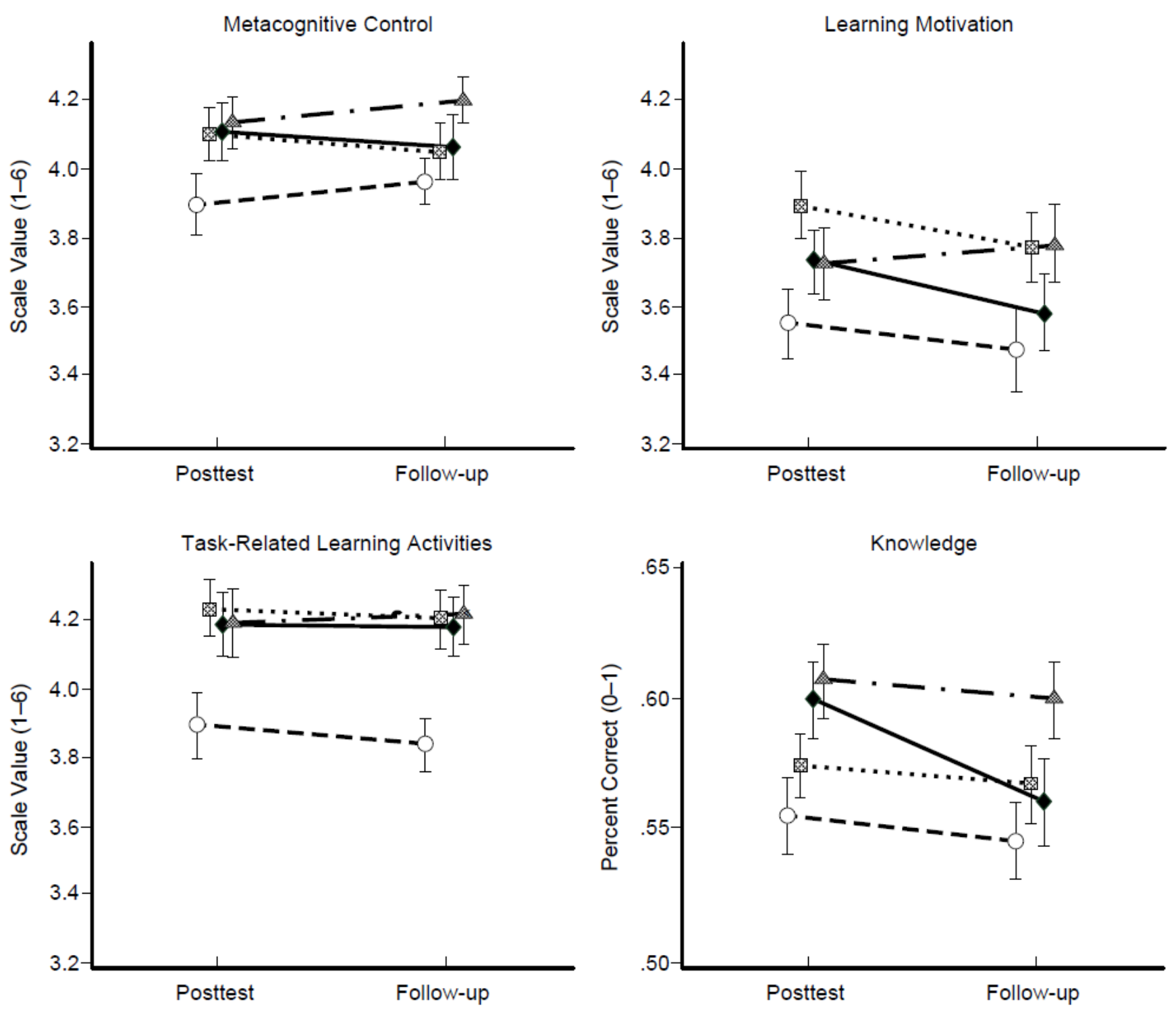

Figure 2. Estimated covariate marginal means and standard errors calculated with the corresponding pretest values as covariates for participants receiving no prompts (circle), metacognitive prompts (square), motivational regulation prompts (diamond), or both types od prompts (triangle). Consequently, group differences represent differences in the change from pretest to posttest or follow-up.

are its innovative focus on prompting motivational regulation strategies (which are theoretically superordinate but were ignored in prior research to the best of our knowledge), the rigorous experimental design (although embedded in an externally valid regular instructional context of a lecture), the consideration of multiple outcomes (derived from a proposed model that specifies their interplay), and the consideration of longterm effects.

In contrast to motivational regulation prompts, metacognitive prompts were already analyzed in a growing body of research (e.g., Bannert \& Mengelkamp, 2013).
The present results for the prompting of metacognitive strategies replicate prior findings generally. Confirming the hypothesized model of proximal and distal prompting effects, metacognitive prompts led to more metacognitive control, an elaboration of the learning material to a larger extent and better persistence when learning as well as better scores on a knowledge test (Hypothesis 1). Results from path modelling the changes induced by the prompts were in line with this causal order of the effects of metacognitive prompts. The results are also in concordance with the theoretical expectation that metacognitive control is functional for 


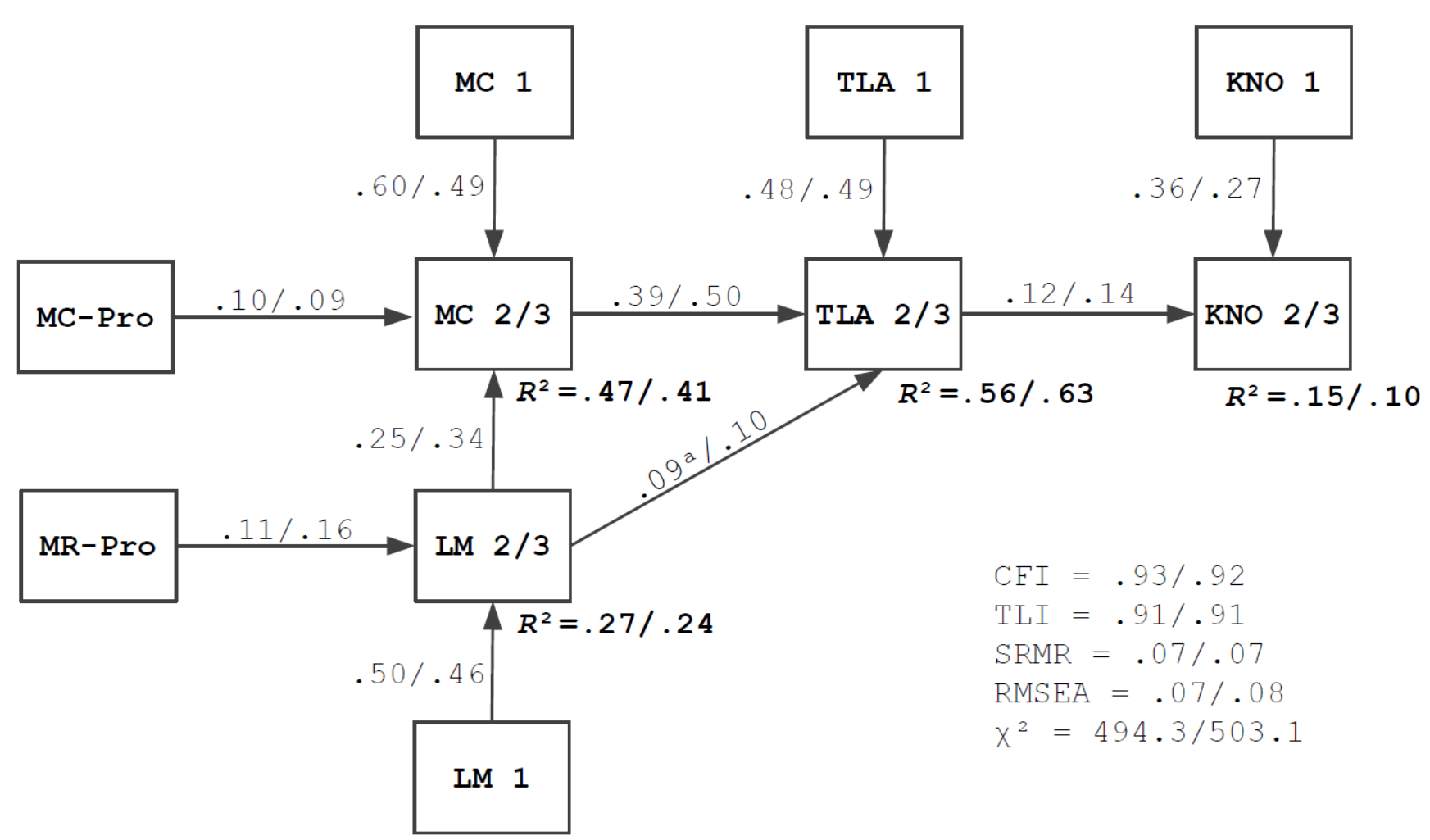

Figure 3. Path modeling of the changes in metacognitive control (MC), learning motivation (LM), task-related learning activities (TLA), and knowledge (KNO) from pretest to posttest and follow-up, respectively, in dependence of the presentation of metacognitive prompts (MC-Pro) and motivational regulation prompts (MR-Pro). Coefficients before the slash refer to the model of changes from pretest to posttest, while coefficients after the slash refer to the model of changes from pretest to follow-up (all paths: $p<.05 ;{ }^{\mathrm{a}} p=.051$ ).

learning processes with challenging topics (Azevedo \& Hadwin, 2005; Graesser et al., 2005). It is also in line with other experimental studies that prompted metacognitive strategies (Bannert, 2009; Bannert \& Mengelkamp, 2013; Bannert \& Reimann, 2012; Hübner et al., 2010; Lin, 2001; Lin \& Lehman, 1999; Schmidt et al., 2012).

The effectiveness of motivational regulation prompts could likewise be confirmed as postulated in the research model. Receiving motivational regulation prompts led students to employ more motivational regulation strategies, have better learning motivation (i.e., a better subjective task value), realize stronger metacognitive control, and use more functional task-related learning activities (i.e., using more cognitive strategies and being more persistent), as well as scoring higher on knowledge tests (Hypothesis 2). Remarkably, a knowledge effect of motivational regulation prompts was also found for students' performances in an exam ten weeks later. These results accentuate the prolificacy of motivational regulation prompts and assert the theo- retical assumptions that motivational regulation strategies are an especially important and superordinate SRL strategy that influences metacognitive and cognitive strategies (Boekaerts, 1999; Schwinger et al., 2009; Wolters, 2003). This assumption was particularly supported by the pattern that motivational regulation prompts supported metacognitive control but metacognitive prompts did not support task value. Results from path modelling of the changes induced by the two types of prompts were in line with our assumptions: Motivational regulation prompts support learning motivation, which in turn has a positive impact on task-related learning activities and knowledge acquisition-with the corresponding effects being transmitted to some degree directly and to some degree indirectly via an improved metacognitive control (Hypothesis 4). Obviously, the superordinate character of motivational regulation strategies in the process of SRL (Boekaerts, 1999) implies particularly good opportunities to utilize them for promoting SRL. Nevertheless, when discussing these findings, it is to be kept in mind that in this 
study we focused motivational regulation on the regulation of one's task value. Future research might expand motivational regulation prompts by investigating other motivational regulation strategies (e.g., goal based or expectancy-focussed strategies; Engelschalk, Steuer \& Dresel, 2016; Schwinger \& Otterpohl, 2017) that might have different effects. Therefore, an investigation of such strategies would contribute to a more detailed understanding of the potential of motivational regulation prompts. Similarly, future research might benefit from looking at the investigated processes in a more differentiated matter, e.g., by examining the specific contributions of different aspects of metacognition to the mediational effect.

Although there was a statistically significant interaction effect for task-related learning activities, the results did not support the hypotheses of metacognitive and motivational regulation prompts eventuating in additive effects in general (Hypothesis 3). By means of participants' additional comments (captured with an open question at the end of the T3 questionnaire), it was determined that about half of the participants (who left a comment) stated not having had sufficient time when learning. It has to be kept in mind that the learning environment was developed with the intention to challenge the participants with its level of difficulty in order to require the use of SRL strategies for high learning outcomes. These results indicate that the participants would have required significantly more time than expected by the researchers and provided within the learning session in order to effectively work with the learning environment and the presented prompts. It has been noted that in some cases learners may find prompting intrusive (Salomon \& Globerson, 1987) and reject the prompted message. This was quite seldom the case in the present study (less than five percent left a comment indicating that the prompts were perceived as disturbing). Nevertheless, it is assumed that SRLprompting requires additional cognitive capacities, which could be partly compensated for by a confrontation with too much learning content in an insufficient time window (Sweller, Van Merrienboer, \& Paas, 1998). This could, in light of cognitive load theory, offer an alternative explanation as to why being presented with both types of prompts did not yield superior effects regarding only metacognitive or motivational regulation prompts.

The prompted effects were remarkably stable. This was especially true for the effects of motivational regulation prompts, which were still present in the students' performance scores at the end of the semester. The observed effect sizes were small to moderate in the classification by Cohen (1988). Nevertheless they were in the expected and for the present context typical range, meaningful, and of practical relevance (e.g., effects on actual exam performance). Keeping further in mind that the students regarded only a few prompts within a short learning period of less than an hour, the prompts appear even more influential than expressed by the bare effect sizes. On a descriptive level, the motivational regulation prompts had a slightly stronger impact than metacognitive prompts, especially with regard to long-term effects. Although these differences could not be tested statistically in the present study, they are theoretically sensible (facing the theoretically prominent role of motivational regulation) and also practically expected (being asked to think about the personal relevance of a given topic might be practically realizable more easily than looking for methods to render the current learning process more effective, especially when not having sufficient time to think about the prompted instruction). Therefore a practical implication for instructors wishing to improve student task engagement and performance may be to focus especially on motivational regulation prompts.

\section{Limitations}

A limitation of the study is that self-reports have been employed to gain insight into the participants' learning behavior (this might be especially critical for the employment of metacognitive and motivational regulation strategies); however this method is very suitable for the assessment of motivation and, most importantly, more objective variables like knowledge gains and exam performance were in line with the results as well. Moreover, the examined population was limited to university freshmen. It is unclear to which degree the results can be generalized to other populations, e.g., whether the prompts already work for secondary school students (with presumably fewer competencies to self-regulate their learning) or whether they still work for more advanced university students (who may employ the prompted strategies already automatically). Lastly, we also have to acknowledge that several participants stated not having noticed the prompts. While this might in part be due to external reasons (e.g., time constraints, unfamiliarity with the learning environment), it also implies that the way our prompts were designed (rather non-invasive as to not disturb the students' learning processes) might not have been effective for every single learner. Future research might therefore benefit from trying to make the prompts more prominent so that everyone can profit from them. 


\section{Conclusions}

We found motivational regulation prompts to have substantial supportive effects on task value, metacognitive control, task-related learning activities as well as knowledge and performance. These effects were in line with a theoretical model specifying proximal and distal effects of metacognitive and motivational regulation prompts. It can be concluded that motivational regulation prompts could be an effective scaffold to support SRL with digital media. Since task value and its regulation play a superior role in SRL they have the potential to function as a comprehensive aid with positive impacts on a variety of aspects and outcomes of the learning process. Although wider in their range of positive effects, motivational regulation prompts may not be weaker in their effectiveness on single characteristics than metacognitive prompts. Nevertheless, followup research is necessary to determine mutual severity and possible interplay. Also, it should be investigated whether the prompted effects are domain-specific or generalizable and which situational conditions (e.g., sufficient time) are required for student compliance with prompts.

\section{References}

Azevedo, R. (2005). Computer environments as metacognitive tools for enhancing learning. Educational Psychologist, 40, 193-197. doi:10.1207/s15326985ep4004_1

Azevedo, R. (2008). The role of self-regulation in learning about science with hypermedia. In D. Robinson \& G. Schraw (Eds.), Recent innovations in educational technology that facilitate student learning (pp. 127-156). Charlotte, NC: Information Age Publishing.

Azevedo, R., \& Cromley, J. (2004). Does training on selfregulated learning facilitate students' learning with hypermedia? Journal of Educational Psychology, 96, 523535. doi:10.1037/0022-0663.96.3.523

Azevedo, R., \& Hadwin, A. (2005). Scaffolding self-regulated learning and metacognition: Implications for the design of computer-based scaffolds. Instructional Science, 33, 367-379. doi:10.1007/s11251-005-1272-9

Bannert, M. (2009). Promoting self-regulated learning through prompts. Zeitschrift für Pädagogische Psychologie/Journal of Pedagogical Psychology, 23, 139-145. doi:10.1024/1010-0652.23.2.139

Bannert, M., Hildebrand, M., \& Mengelkamp, C. (2009). Effects of a metacognitive support device in learning environments. Computers in Human Behavior, 25, 829-835. doi:10.1016/j.chb.2008.07.002

Bannert, M., \& Mengelkamp, C. (2013). Scaffolding hypermedia learning through metacognitive prompts. In R. Azevedo \& V. Aleven (Eds.), International handbook of metacognition and learning technologies (pp. 171-186). New York, NY: Springer.

Bannert, M., \& Reimann, P. (2012). Supporting self-regulated hypermedia learning through prompts. Instructional Science, 40, 193-211. doi:10.1007/s11251-011-9167-4

Baumert, J., Heyn, S., \& Köller, O. (1992). Das Kieler Lernstrategien-Inventar [Kiel inventory of learning strategies]. Kiel, Germany: Institute for Science Education at the University of Kiel.

Berthold, K., Nückles, M., \& Renkl, A. (2007). Do learning protocols support learning strategies and outcomes? The role of cognitive and metacognitive prompts. Learning and Instruction, 17, 564-577. doi:10.1016/j.learninstruc.2007.09.007

Boekaerts, M. (1997). Self-regulated learning: A new concept embraced by researchers, policy makers, educators, teachers, and students. Learning and Instruction, 7, 161186. doi:10.1016/s0959-4752(96)00015-1

Boekaerts, M. (1999). Self-regulated learning: Where are we today? International Journal of Educational Research, 31, 445-457. doi:10.1016/s0883-0355(99)00014-2

Boekaerts, M., Pintrich, P., \& Zeidner, M. (Eds.). (2005). Handbook of self regulation. Burlington, NJ: Elsevier.

Chiu, C.-M., Sun, S.-Y., Sun, P.-S., \& Ju, T. (2007). An empirical analysis of the antecedents of web-based learning continuance. Computers \& Education, 49, 1224-1245. doi:10.1016/j.compedu.2006.01.01

Cohen, J. (1988). Statistical power analysis for the behavioral sciences (2nd ed.). New York, NY: Academic Press.

Davis, E. (2000). Scaffolding students' knowledge integration: Prompts for reflection in KIE. International Journal of Science Education, 22, 819-837. doi:10.1080/095006900412293

Devolder, A., van Braak, J., \& Tondeur, J. (2012). Supporting self-regulated learning in computer-based learning environments: Systematic review of effects of scaffolding in the domain of science education. Journal of Computer Assisted Learning, 28, 557-573. doi:10.1111/j.1365-2729.2011.00476.x

Dewitte, S., \& Lens, W. (1999). Volition: Use with measure. Learning and Individual Differences, 11, 321-333. doi:10.1016/s1041-6080(99)80006-5

Dresel, M., \& Haugwitz, M. (2006). The relationship between cognitive abilities and self-regulated learning: Evidence for interactions with academic self-concept and gender. High Ability Studies, 16, 201-218. doi:10.1080/13598130600618066

Engelschalk, T., Steuer, G. \& Dresel, M. (2016). Effectiveness of motivational regulation: Dependence on specific motivational problems. Learning and Individual Differences, 52, 72-78. doi:10.1016/j.lindif.2016.10.011

Engelschalk, T., Steuer, G., \& Dresel, M. (2017). Quantity and quality of motivational regulation among university students. Educational Psychology. Advance online publication. doi:10.1080/01443410.2017.1322177 
Garcia, T. (1999). Maintaining the motivation to learn: An introduction to this special issue of learning and individual differences. Learning and Individual Differences, 11, 231-232. doi:10.1016/s1041-6080(99)80001-6

Gold, A., \& Souvignier, E. (2000). Lernstrategien und Lernerfolg [Learning strategies and learning success]. Paper presented at the 42nd Conference of the German Psychological Society, Jena, Germany.

Graesser, A., McNamara, D. S., \& VanLehn, K. (2005). Scaffolding deep comprehension strategies through Point\&Query, AutoTutor, and iStart. Educational Psychologist, $\quad 40, \quad$ 225-234. doi:10.1207/s15326985ep4004_4

Grunschel, C., Schwinger, M., Steinmayr, R., \& Fries, S. (2016). Effects of using motivational regulation strategies on students' academic procrastination, academic performance, and well-being. Learning and Individual Differences, 49, 162-170. doi:10.1016/j.lindif.2016.06.008

Hsu, Y., Ching, Y., Mathews, J., \& Carr-Chellman, A. (2009). Undergraduate students' self-regulated learning experience in web-based learning environments. Quarterly Review of Distance Education, 10, 109-121. Retrieved from http://itecideas.pbworks.com/f/44895673nn.pdf

Hübner, S., Nückles, M., \& Renkl, A. (2010). Writing learning journals: Instructional support to overcome learningstrategy deficits. Learning and Instruction, 20, 18-29. doi:10.1016/j.learninstruc.2008.12.001

Hulleman, C., \& Harackiewicz, J. (2009). Promoting interest and performance in high school science classes. Science, 326, 1410-1412. doi:10.1126/science.1177067

Kauffman, D. (2004). Self-regulated learning in web-based environments: Instructional tools designed to facilitate cognitive strategy use, metacognitive processing, and motivational beliefs. Journal of Educational Computing Research, 30, 139-161. doi:10.2190/ax2d-y9vm-v7pxOtad

Lehmann, T., Hähnlein, I., \& Ifenthaler, D. (2014). Cognitive, metacognitive and motivational perspectives on preflection in self-regulated online learning. Computers in Human Behavior, 32, 313-323. doi:10.1016/j.chb.2013.07.051

Li, C.-S., \& Irby, B. (2008). An overview of online education: Attractiveness, benefits, challenges, concerns and recommendations. College Student Journal, 42, 302307. Retrieved from http://eric.ed.gov/?id=EJ816925

Lin, X. (2001). Designing metacognitive activities. Educational Technology Research and Development, 49, 10421629. doi:10.1007/bf02504926

Lin, X., \& Lehman, J. (1999). Supporting learning of variable control in a computer-based biology environment: Effects of prompting college students to reflect on their own thinking. Journal of Research in Science Teaching, 36, 837-858. doi:10.1002/(sici)10982736(199909)36:7<837::aid-tea6>3.0.co;2-u

Moos, D., \& Azevedo, R. (2008). Exploring the fluctuation of motivation and use of self-regulatory processes during learning with hypermedia. Instructional Science, 36, 203-231. doi:10.1007/s11251-007-9028-3

Nückles, M., Hübner, S., Dümer, S., \& Renkl, A. (2010). Expertise reversal effects in writing-to-learn. Instructional Science, 38, 237-258. doi:10.1007/s11251-009-9106-9

Nückles, M., Schwonke, R., Berthold, K., \& Renkl, A. (2004). The use of public learning diaries in blended learning. Journal of Educational Media, 29, 49-66. doi:10.1080/1358165042000186271

Pan, W., \& Tang, M. (2004). Examining the effectiveness of innovative instructional methods on reducing statistics anxiety for graduate students in the social sciences. Journal of Instructional Psychology, 31, 149-159. Retrieved from eric.ed.gov/?id=EJ774076

Pintrich, P. R. (1999). Taking control of research on volitional control. Challenges for future theory and research. Learning and Individual Differences, 11, 335-354. doi:10.1016/S1041-6080(99)80007-7

Pintrich, P. (2000). The role of goal orientation in self-regulated learning. In M. Boekaerts, P. Pintrich, \& M. Zeidner (Eds.), Handbook of self-regulation (pp. 451-502). San Diego, CA: Academic Press.

Pintrich, P., \& De Groot, E. (1990). Motivational and selfregulated learning components of classroom academic performance. Journal of Educational Psychology, 82, 33-40. doi:10.1037/0022-0663.82.1.33

Pintrich, P., \& Zusho, A. (2002). The development of academic self-regulation: The role of cognitive and motivational factors. In A. Wigfield \& J. Eccles (Eds.), Development of achievement motivation (pp. 250-284). San Diego, CA: Academic Press.

Pintrich, P. (2004). A conceptual framework for assessing motivation and self-regulated learning in college students. Educational Psychology Review, 16, 385-407. doi:10.1007/s 10648-004-0006-X

Puntambekar, S., \& Hubscher, R. (2005). Tools for scaffolding students in a complex learning environment: What have we gained and what have we missed? Educational Psychologist, 40, 1-12. doi:10.1207/s15326985ep4001_1

Reid, A., \& Petocz, P. (2002). Students' conceptions of statistics: A phenomenographic study. Journal of Statistics Education, 10, 1-18. Retrieved from www.amstat.org/publications/jse/v10n2/reid.html

Reigeluth, C., \& Stein, F. (1983). The elaboration theory of instruction. In M. Reigeluth (Ed.), Instructional design theories and models: An overview of their current states (pp. 335-383). Hillsdale, NJ: Lawrence Erlbaum.

Rosenshine, B., Meister, C., \& Chapman, S. (1996). Teaching students to generate questions: A review of the intervention studies. Review of Educational Research, 66 , 181-221. doi:10.3102/00346543066002181

Salomon, G., \& Globerson, T. (1987). Skill may not be enough: The role of mindfulness in learning and transfer. International Journal of Educational Research, 11, 623637. doi:10.1016/0883-0355(87)90006-1 
Sansone, C., Weir, C., Harpster, L., \& Morgan, C. (1992). Once a boring task always a boring task? Interest as a self-regulatory mechanism. Journal of Personality and Social Psychology, 63, 379-390. doi:10.1037/00223514.63.3.379

Schmidt, K., Maier, J., \& Nückles, M. (2012). Writing about the personal utility of learning contents in a learning journal improves learning motivation and comprehension. Education Research International, 2012, 1-10. doi:10.1155/2012/319463

Schunk, D., \& Zimmerman, B. (2012). Motivation and selfregulated learning: Theory, research, and applications. New York, NY: Routledge.

Schwinger, M., Steinmayr, R., \& Spinath, B. (2009). How do motivational regulation strategies affect achievement: Mediated by effort management and moderated by intelligence. Learning and Individual Differences, 19, 621627. doi:10.1016/j.lindif.2009.08.006

Schwinger, M., Steinmayr, R., \& Spinath, B. (2012). Not all roads lead to rome-comparing different types of motivational regulation profiles. Learning and Individual Differences, 22, 269-279. doi:10.1016/j.lindif.2011.12.006

Schwinger, M., von der Laden, T., Spinath, B. (2007). Strategien zur Motivationsregulation und ihre Erfassung [Motivational regulation strategies and their measurement]. Zeitschrift für Entwicklungspsychologie und Pädagogische Psychologie/Journal of Developmental and Educational Psychology, 39, 57-69. doi:10.1026/00498637.39.2.57

Schwinger, M., \& Otterpohl, N. (2017). Which one works best? Considering the relative importance of motivational regulation strategies. Learning and Individual Differences, 53, 122-132. doi:10.1016/j.lindif.2016.12.003

Sweller, J., Van Merrienboer, J. J., \& Paas, F. G. (1998). Cognitive architecture and instructional design. Educational Psychology Review, 10, 251-296. Retrieved from http://link.springer.com/article/10.1023\%2FA\%3A1022193728205

van Loon, A.-M., Ros, A., \& Martens, R. (2012). Motivated learning with digital learning tasks: What about autonomy and structure? Educational Technology Research and Development, 60, 1015-1032. doi:10.0.3.239/s11423-012-9267-0

VanZile-Tamsen, C., \& Livingstone, J. (1999). The differential impact of motivation on the self-regulated strategy use of high- and low-achieving collage students. Journal of College Student Development, 40 (1), 54-60.

Weinstein, C., \& Hume, L. (1998). Study strategies for lifelong learning. Washington, DC: American Psychological Association.

Wigfield, A., \& Eccles, J. (2000). Expectancy-value theory of achievement motivation. Contemporary Educational Psychology, 25, 68-81. doi:10.1007/bf02209024
Wigfield, A., Hoa, L. W., \& Klauda, S. L. (2008). The role of achievement values in the self-regulation of achievement behaviors. In D. Schunk \& B. Zimmerman (Eds.), Motivation and self-regulated learning: Theory, research, and applications (pp. 169-195). New York, NY: Lawrence Erlbaum.

Winne, P., \& Hadwin, A. (2010). Self-regulated learning and socio-cognitive theory. In P. Peterson, E. Baker, \& B. McGaw (Eds.), International encyclopedia of education (pp. 503-508). Amsterdam, Netherlands: Elsevier.

Winne, P. \& Hadwin, A. (2012). The weave of motivation and self-regulated learning. In D. Schunk \& B. Zimmerman (Eds.), Motivation and self-regulated learning. Theory, research and applications (pp. 297-314). New York, NY: Routledge.

Winters, F., Greene, J., \& Costich, C. (2008). Self-regulation of learning within computer-based learning environments: A critical analysis. Educational Psychology Review, 20, 429-444. doi:10.1007/s10648-008-9080-9

Wolters, C. (1999). The relation between high school students' motivational regulation and their use of learning strategies, effort, and classroom performance. Learning and Individual Differences, 11, 281-299. doi:10.1016/s1041-6080(99)80004-1

Wolters, C. (2003). Regulation of motivation: Evaluating an underemphasized aspect of self-regulated learning. $E d u$ cational Psychologist, 38, 189-205. doi:10.1207/s15326985ep3804_1

Wolters, C. (2004). Advancing achievement goal theory: Using goal structures and goal orientations to predict students' motivation, cognition, and achievement. Journal of Educational Psychology, 96, 236-254. doi:10.1037/0022-0663.96.2.236

Wolters, C., \& Benzon, M. (2013). Assessing and predicting college students' use of strategies for the self-regulation of motivation. The Journal of Experimental Education, 81, 199-221. doi:10.1080/00220973.2012.699901

Ziegler, A., Dresel, M., \& Stöger, H. (2008). Addressees of performance goals. Journal of Educational Psychology, 100, 643-654. doi:10.1037/0022-0663.100.3.643

Zimmerman, B. (1986). Becoming a self-regulated learner: Which are the key subprocesses? Contemporary Educational Psychology, 11, 307-313. doi:10.1016/0361$476 x(86) 90027-5$

Zimmerman, B. (2000). Attaining self-regulated leaming: A social-cognitive perspective. In M. Boekaerts, P. Pintrich, \& M. Zeidner (Eds.), Handbook of self-regulation (pp. 13-39). San Diego, CA: Academic Press.

Note. This is a pre-copyedited, author-produced PDF of an article accepted for publication in Journal of Experimental Education following peer review. This paper is not the copy of record and may not exactly replicate the final, authoritative version of the article. The final article will be available, upon publication, via its DOI. 


\section{Footnotes}

${ }^{1}$ All prompts are available as an electronic supplement.

${ }^{2}$ Participants were classified as non-recognizing of the prompts when they reported that they noticed none or, at best, one of the prompts ("How many hints in orange boxes did you recognize?").

${ }^{3}$ Internal consistencies should be interpreted with keeping in mind that the measured strategies were rather heterogeneous and a uniform distribution on each strategy was not to be expected. As such, the scales offer, despite borderline satisfactory internal consistencies, a comprehensive although rough total of the students' employment of metacognitive and motivational regulation strategies, respectively, that is sufficient for the purpose of manipulation check.

${ }^{4}$ Separate analyses of the prompting effects on the level of the task value facets attainment value, utility value, and intrinsic value resulted in similar patterns of effects as the analyses with the conflated task value variable.

${ }^{5}$ Towards the employment of motivational regulation strategies there was also a statistically significant interaction effect $\left(F(1,211)=6.67, p=.01, \eta^{2}=.031\right)$, indicating that students used more motivational regulation strategies when they also received - in addition to motivational regulation prompts - metacognitive prompts. The interaction effect for metacognitive control was not statistically significant $\left(F(1,211)=0.95, p=.33, \eta^{2}=.005\right)$.

${ }^{6}$ The estimated means (after controlling for T1 knowledge) were $M=.61$ for the control group, $M=.62$ for metacognitive prompts, $M=.64$ for motivational regulation prompts, and $M=.65$ for both prompts. 